\title{
Dynamic Nonlinear Analysis of an Irregular Office Building
}

\author{
Haitao Liu ${ }^{1}$, Shuchang Sun ${ }^{1}$, Maoxing $\mathrm{Xu}^{1}$ and Yiliang Peng ${ }^{1}$ \\ ${ }^{1}$ Powerchina Henan Electric Power Survey \& Design Institute Corporation Limited,Zhengzhou, 450007, China
}

\begin{abstract}
The common analysis methods of structural building include the response spectrum, static nonlinear analysis (pushover) and dynamic nonlinear analysis method. Meanwhile, for the analysis of irregular structures, dynamic nonlinear analysis method could accurately simulate the seismic response of structure under rare earthquake. In this paper, the dynamic nonlinear analysis was carried out to evaluate the seismic performance of an office building with irregular in plan and in elevation. The simulation results show that the maximum inter story-drift angle can satisfy the requirement in the nation code. Few shear walls exceeded the concrete yield compressive stress and most of the shear walls remained in the elastic stage. Most frame columns were within the component acceptance criterion of IO. By the above analysis results, it can be judged that the seismic capacity of the building structure can reach the seismic performance objectives in the code.
\end{abstract}

\section{Introduction}

Past earthquake events and the shaking table tests have shown that the irregular structures suffer more serious damage due to the inconsistency of the mass center and the rigidity center[1-2]. The plan irregular structures present torsional vibration under earthquake actions. And for the structures with elevation irregularity, the specific stories may suffer more serious damages. Thus, it is necessary to evaluate the seismic performance for the structure with characteristic plan or elevation irregularity. The proposed project of office building in this paper has 16 floors on the ground and 2 layers underground, as shown in Fig.1. The frame-shear wall structure system was applied in the building. The building is located in Zhengzhou and the main building has a construction area of $78100 \mathrm{~m} 2$. The total height of the structure is $61.2 \mathrm{~m}$, which can meet the requirement in the nation code of GB 50011[3]. Whereas, the maximum torsional displacement ratio was 1.37 and the eccentricity ratio according to the coordinates of mass center and rigidity center in the third floor was 0.87 , which were all exceed the requirement in the nation code of GB 50011[3]. Moreover, the effective width of the fourth floor was only 0.125 , as shown in Fig.2, which was characterized by the floor slab discontinuity. The construction areas decreased by $27 \%$, $32 \%$ and $40 \%$ in the ninth, fourteenth and fifteenth floors, respectively, which was characterized by the elevation irregular buildings. As the building belongs to the irregular building in the plan and elevation, it was required to evaluate the seismic performance under rare earthquake.

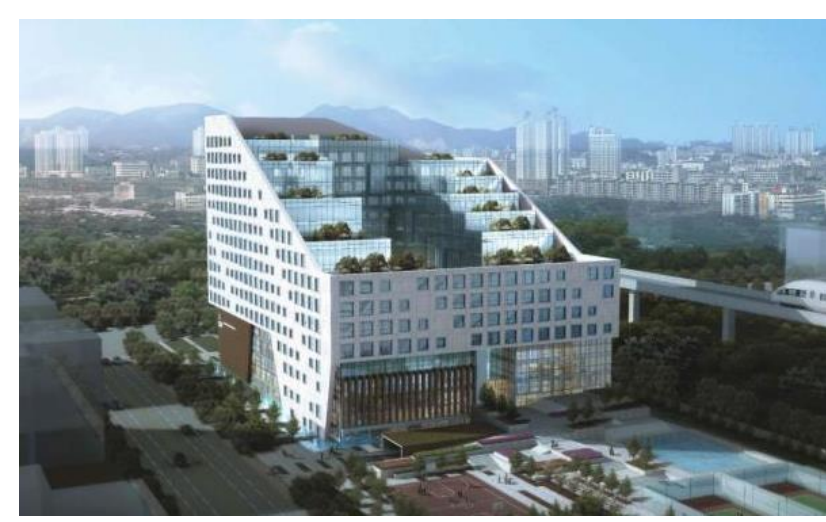

Fig. 1. Architecture effect chart of office building

\section{Modeling and analytical methods}

\subsection{Material information}

C30 concrete was used in the beams, slabs and shear walls above the twelfth floor. Frame columns and shear walls in the ninth floor to eleventh floor were made of C40 concrete. Frame columns and shear walls below the eighth floor were made of C50 concrete. Steel bars with the grade of HRB400 were used in the concrete component. The mechanical properties of material used in the building are listed in Table 1 . 


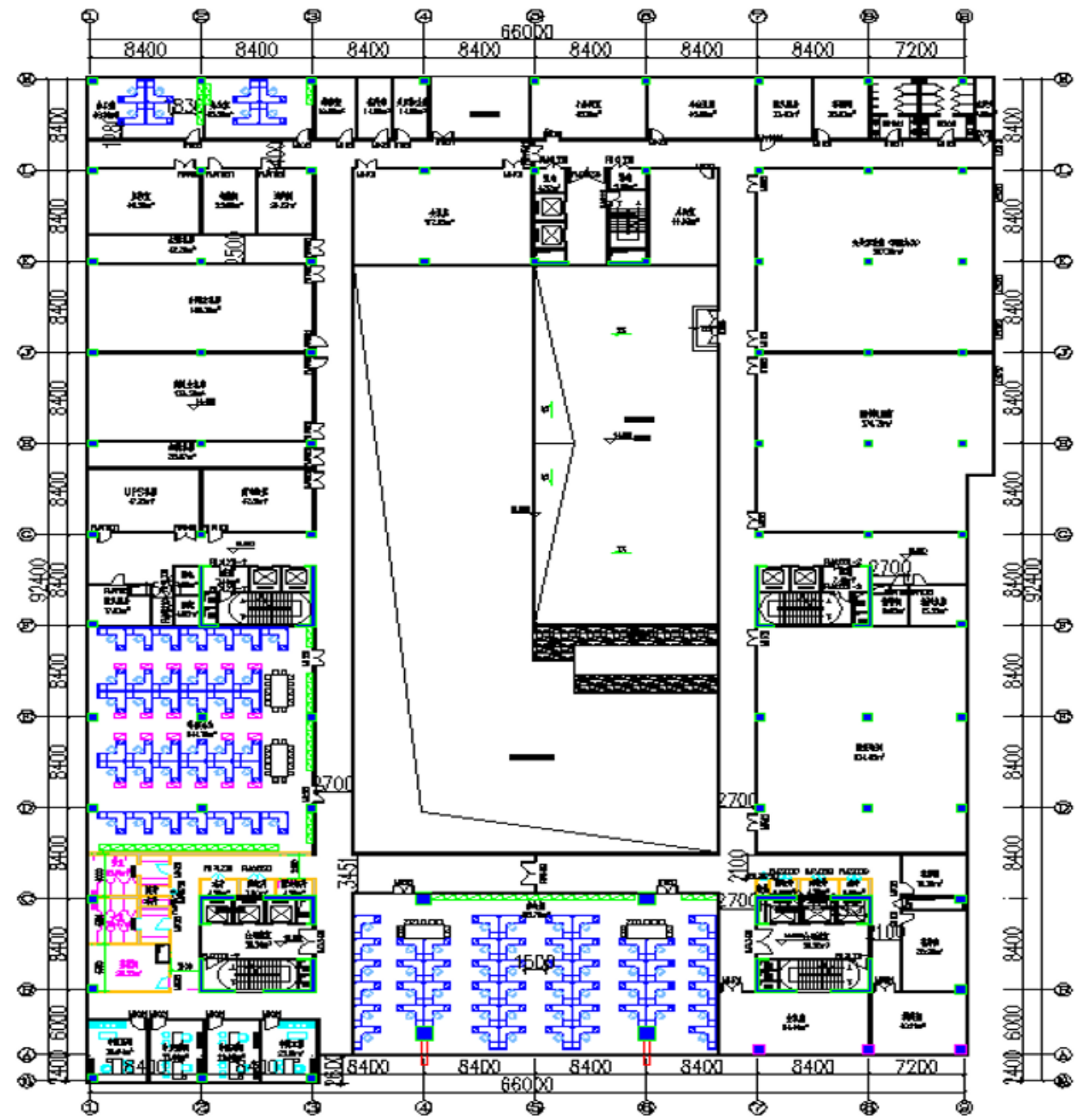

Fig. 2. Structural layout in the fourth floor

Table 1. Mechanical properties of material

\begin{tabular}{|c|c|c|c|}
\hline Material & Grade & $\begin{array}{c}\text { Compression } \\
{\left[\mathrm{N} / \mathrm{mm}^{2}\right]}\end{array}$ & $\begin{array}{c}\text { Tension } \\
{\left[\mathrm{N} / \mathrm{mm}^{2}\right]}\end{array}$ \\
\hline \multirow{3}{*}{ Concrete } & $\mathrm{C} 30$ & 14.3 & 1.43 \\
\cline { 2 - 4 } & $\mathrm{C} 40$ & 19.1 & 2.39 \\
\cline { 2 - 4 } & $\mathrm{C} 50$ & 23.1 & 2.64 \\
\hline Steel bar & HRB400 & 360 & 360 \\
\hline
\end{tabular}

Note: the value in China Code for design of masonry structures (GB50010-2010)[4]

\subsection{Finite element model}

The analytical methods to evaluate the seismic performance of building include mode-superposition response spectrum analysis method, static nonlinear analysis (pushover) and dynamic nonlinear analysis method. Whereas, some structural components may reaches the elastoplastic phase under rare earthquake, which is not satisfy the structural components elastic assumption of mode-superposition response spectrum analysis method. Moreover, the static nonlinear analysis method is usually suitable for the regular buildings. Thus, the dynamic nonlinear analysis method was used to evaluate the seismic performance of building according to the software of Perform-3d [5] in this paper. Frame compound components of beam type and column type were used to simulate the beams and frame columns, respectively. The beam type compound components were consisted of two inelastic segments defined by the fiber cross sections and one elastic cross-section segment defined by uniform cross section, as shown in Fig. 3(a). The column type compound components were also consisted of two inelastic segments and one elastic cross-section segment. The fiber cross sections for the beam and column type compound components are shown in Fig. 3(b) (c). The shear wall element in Perform-3d was defined by specify the shear properties and axial-bending properties to the shear wall compound component, as shown in Fig.4.

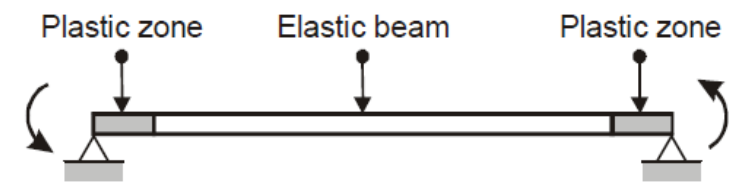

(a) Frame compound component 


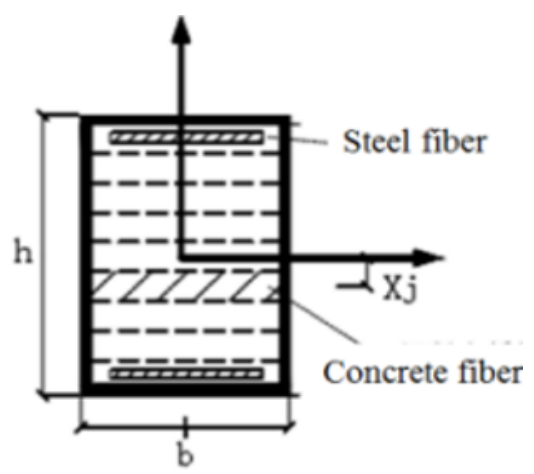

(b) Fiber section for concrete beam

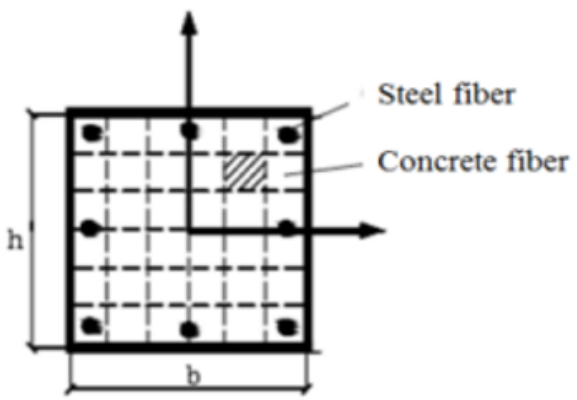

(c) Fiber section for frame column

Fig. 3. Definition of concrete column and beam in Perform-3d

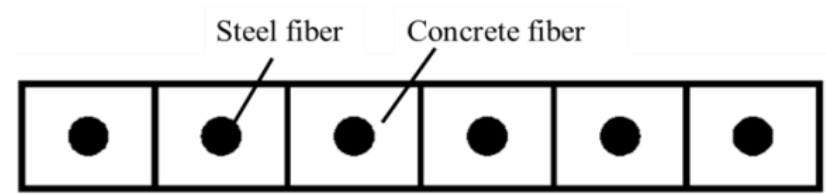

Fig. 4. Definition of shear wall section in Perform-3d

The trilinear model was used to simulate the concrete stress-strain constitutive relations, which could consider the influence of strength loss and stiffness degradation. The control points in the trilinear model were calculated according to the concrete constitutive laws in the nation code of GB50010-2010[4] as shown in Fig. 5(a). The steel bar constitutive model is shown in Fig. 5(b).

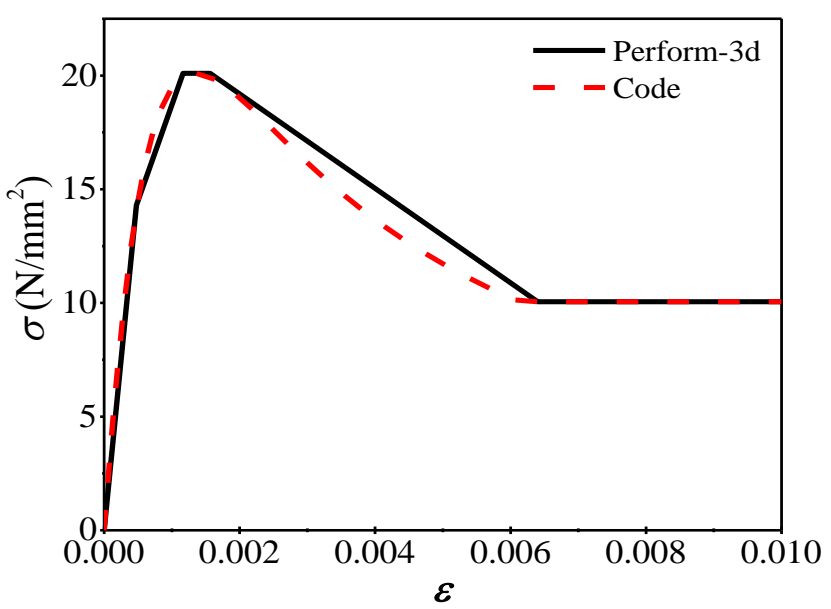

(a) $\mathrm{C} 30$ concrete

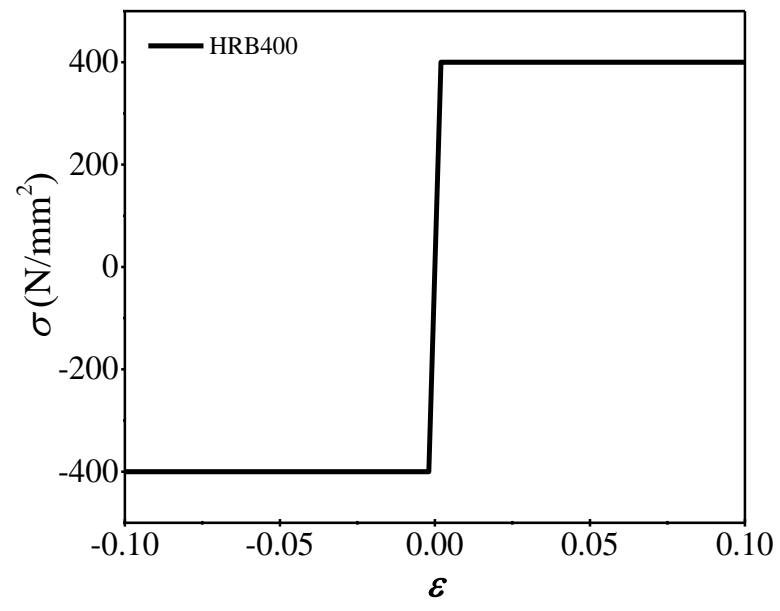

(b) Steel bars of HRB400

Fig. 5. Constitutive relations for concrete and steel bar

\subsection{Earthquake selection}

Two crude seismic waves and one artificial wave were screened according to the response spectrum defined in the China code of GB50011[3]. Fig.6 shows the time history and the acceleration response spectrum of the artificial waves. The seismic waves were applied in the direction of $\mathrm{X}$-axis and the $\mathrm{Y}$-axis at the same time and the peak acceleration ratio of $\mathrm{Y}$-axis to the $\mathrm{X}$-axis is assigned to be 1 to 0.85 , which is specified by China code.

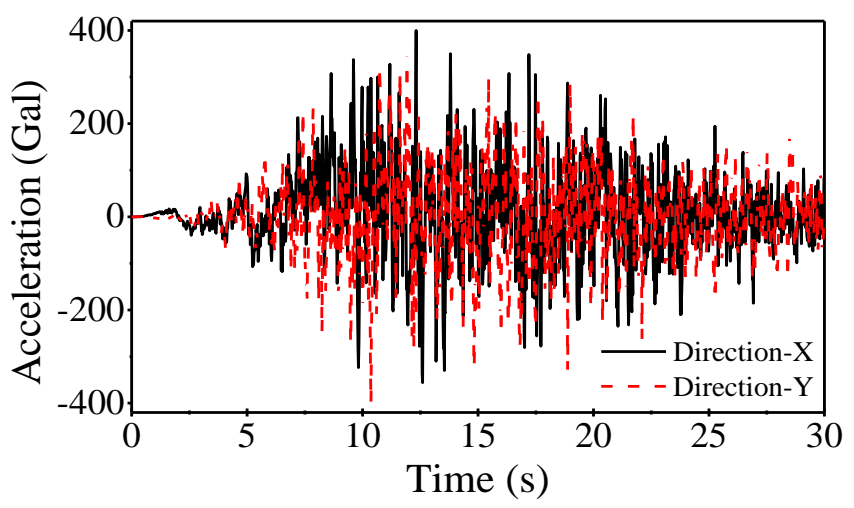

(a) Time history curves

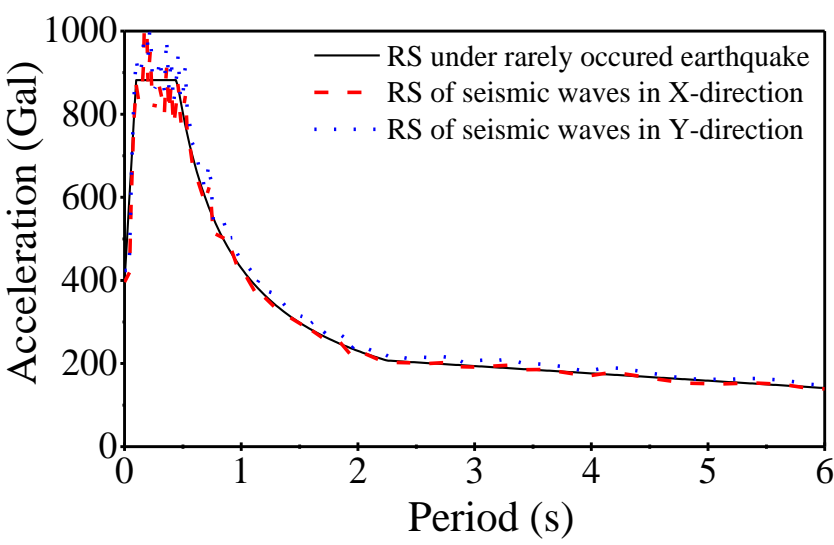

(b) Acceleration response spectrum

Fig. 6. Time history and acceleration response spectrum 


\section{Analytical results}

\subsection{Self-vibration periods and vibration modes}

In order to obtain the free-vibration characteristics of the building and verify the finite element model of Perform-3d, software of PKPM was applied to model analysis. The first three vibration modes are shown in Fig. 7 and Table 5 lists the detail modal analysis results. As shown in in Fig. 7 and Table 5, the first two mode shapes were translated in $\mathrm{X}$ direction and $\mathrm{Y}$ direction, respectively. The third mode shape was torsion mode shape. Whereas, the first two mode shapes included some torsional components as the irregularity in the plan and elevation of building.

Table 2. Comparison of the periods [s]

\begin{tabular}{|c|c|c|c|c|c|c|}
\hline $\begin{array}{c}\text { Mode } \\
\text { Shape NO. }\end{array}$ & 1 & 2 & 3 & 4 & 5 & 6 \\
\hline PKPM & 1.84 & 1.79 & 1.64 & 0.74 & 0.61 & 0.53 \\
\hline Perform-3d & 2.03 & 2.02 & 1.83 & 0.81 & 0.66 & 0.61 \\
\hline $\begin{array}{c}\text { Vibration } \\
\text { Direction }\end{array}$ & $\mathrm{X}$ & $\mathrm{Y}$ & Torsion & & & \\
\hline
\end{tabular}

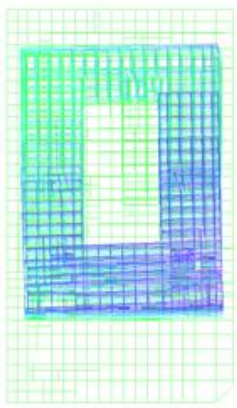

(a) First period

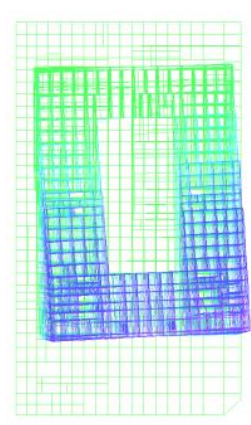

(b) Second period

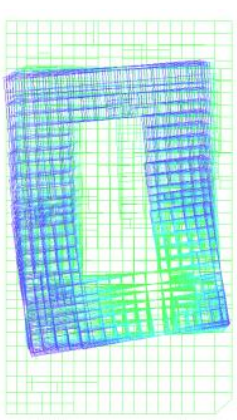

(c) Third period
Fig. 7. First three vibration modes

\subsection{Inter story-drift angle and base shear force}

Fig. 8 shows the distribution of inter story-drift angle under the three seismic waves according to the dynamic nonlinear analysis. It shows that the maximum inter-story drift angle appeared at the top of building. Table 3 lists the maximum inter-story drift angle under occasional earthquake and rare earthquake. As can be seen from Table 3, the maximum inter-story drift angle was $1 / 121$, which can satisfy the requirement of $1 / 100$ in the code of GB50011[3].

Table 3. Inter-storey drift angles (rad)

\begin{tabular}{cccc}
\hline Direction & $\begin{array}{c}\text { Artificial } \\
\text { wave }\end{array}$ & $\begin{array}{c}\text { Natural } \\
\text { wave-I }\end{array}$ & $\begin{array}{c}\text { Natural } \\
\text { wave-II }\end{array}$ \\
\hline $\mathrm{X}$ & $1 / 121$ & $1 / 134$ & $1 / 123$ \\
$\mathrm{Y}$ & $1 / 150$ & $1 / 129$ & $1 / 143$ \\
\hline
\end{tabular}

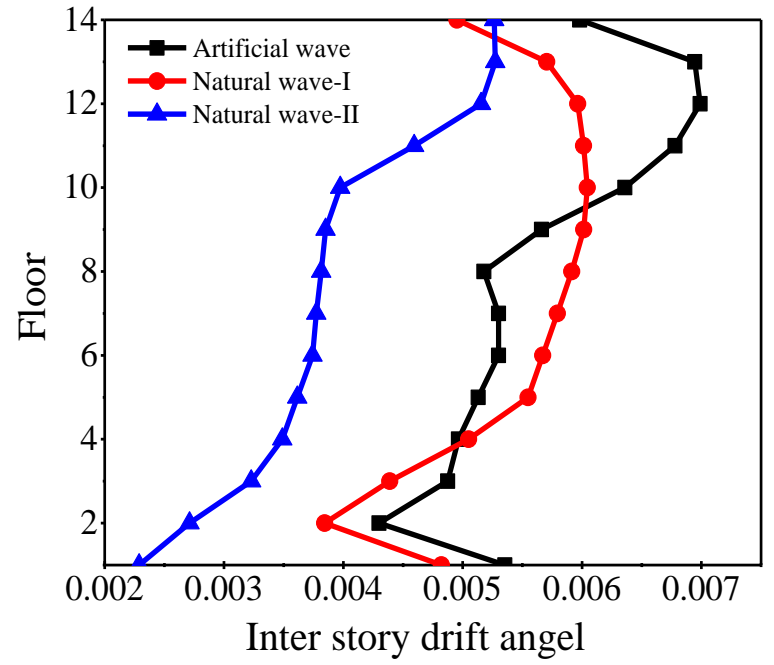

(a) In X-direction

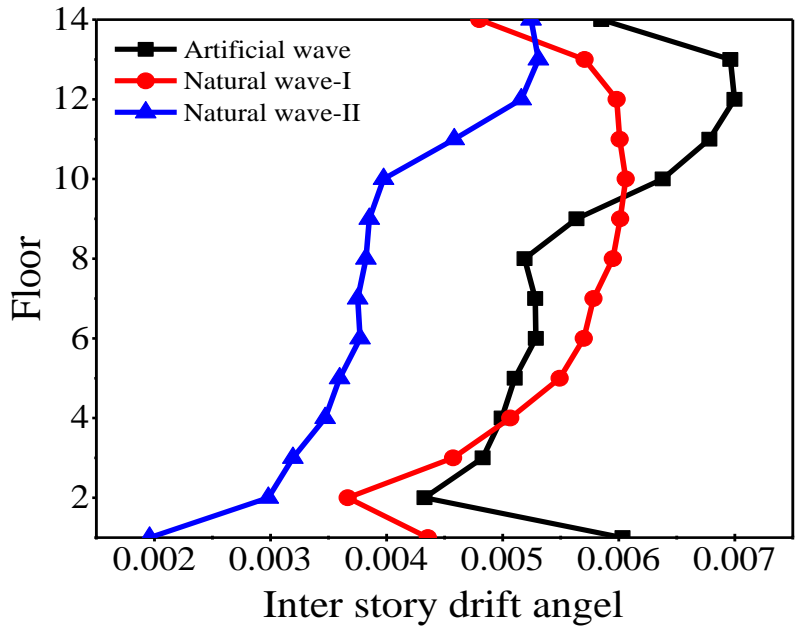

(b) In Y-direction

Fig. 8. Inter story-drift angle distribution under the three seismic waves

Table 4 lists the base shear force of building under occasional earthquake and rare earthquake. It shows that the average value of base shear force under rare earthquake was about 3.5 times the average value under the occasional earthquake.

Table 4. Comparison of base shear under occasional and rare earthquake

\begin{tabular}{|c|c|c|c|c|c|c|}
\hline & \multicolumn{3}{|c|}{ X-Direction } & \multicolumn{3}{c|}{ Y-Direction } \\
\cline { 2 - 7 } & $\begin{array}{c}\mathrm{OE} \\
{[\mathrm{KN}]}\end{array}$ & $\begin{array}{c}\mathrm{RE} \\
{[\mathrm{KN}]}\end{array}$ & $\begin{array}{c}\mathrm{OE} / \\
\mathrm{RE}\end{array}$ & $\begin{array}{c}\mathrm{OE} \\
{[\mathrm{KN}]}\end{array}$ & $\begin{array}{c}\mathrm{RE} \\
{[\mathrm{KN}]}\end{array}$ & $\begin{array}{c}\mathrm{OE} / \\
\mathrm{RE}\end{array}$ \\
\hline $\begin{array}{c}\text { Artificial } \\
\text { wave }\end{array}$ & 31976 & 145348 & 4.55 & 30340 & 149063 & 4.91 \\
\hline $\begin{array}{c}\text { Natural } \\
\text { wave-I }\end{array}$ & 22802 & 100499 & 4.41 & 25410 & 114745 & 4.52 \\
\hline $\begin{array}{c}\text { Natural } \\
\text { wave-II }\end{array}$ & 23373 & 121984 & 5.22 & 21470 & 131695 & 6.13 \\
\hline Average & 26106 & 130796 & 5.06 & 26389 & 139610 & 5.33 \\
\hline
\end{tabular}

OE denotes occasional earthquake; RE denotes rare earthquake; 


\subsection{Damage of structural components}

The structural component damage states were defined according to the code of FEAM-356 [6]. The strain of concrete and reinforcement bars was defined as the damage indicator to evaluate the seismic performance of building structure in FEAM-356. The strain limits corresponding to the seismic design criterion were defined according to the code of FEAM-356. IO refers to the seismic performance of immediate occupancy, LS refers to the seismic performance of life safety and $\mathrm{CP}$ refers to the seismic performance of collapse prevention, respectively. The structural component damage states were presented by different colors in the software of Perform-3d.

Fig. 9 shows the damage condition of the building components under the artificial seismic wave. As can be seen from Fig. 9(a), most frame columns were within the component acceptance criterion of IO, few frame columns in the top of building were within the acceptance criterion of LS and no frame column exceeded the criterion of CP. Fig. 9(b) shows the damage condition of concrete beam. It shows that most concrete beams were within the acceptance criterion of LS and two beams exceeded the criterion of CP. It reflects that the concrete beams efficiently dissipated the seismic energy and to reduce seismic damage of frame columns and shear wall. Fig. 9(c) shows that few shear walls exceeded the acceptance criterion of IO. In order to adequately understand the damage condition of shear wall, the compressive stress-time curves of shear wall in the bottom building are shown in Fig. 10. It shows that the maximum compressive stress of bottom shear wall was $1.696 \times 10^{-3}$, which is less than the ultimate compressive strength of concrete, $3.3 \times 10^{-3}$. It reflected that the shear wall in the building had sufficient seismic capability in rare earthquake.

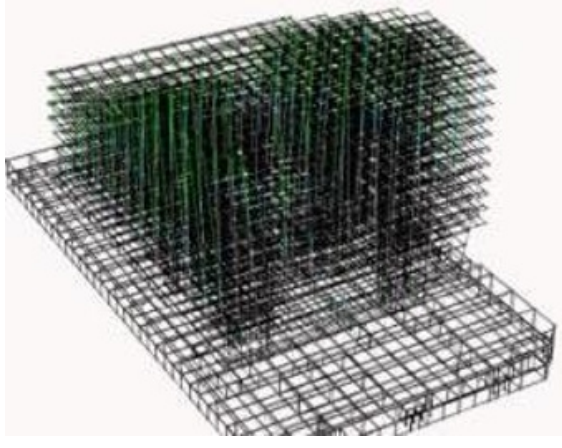

(a) Damage of columns

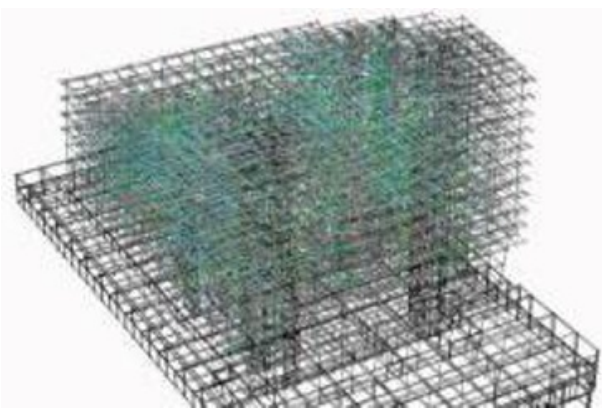

(b) Damage of beams

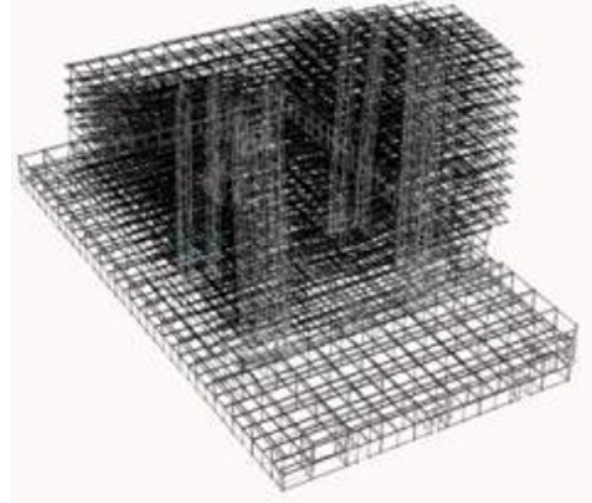

(c) Damage of shear walls

Fig. 9. Damage conditions of structural components

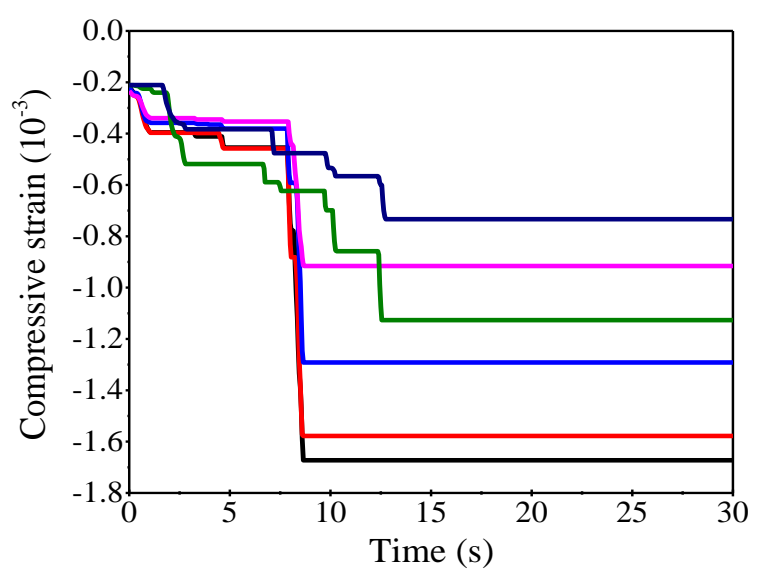

Fig. 10. Concrete compressive strain of shear wall

\section{Conclusion}

This paper evaluated the seismic performance of the irregular building structure in rare earthquake. According to the dynamic nonlinear analyses in the software of Perform-3d, the main conclusions are summarized as follows:

(1) The torsional coupled vibration was observed in the first two periods as the irregular distribution of vertical structural components.

(2) The maximum inter story-drift angle of the building under the three earthquake waves was 1/121, which could meet the drift angle requirement of $1 / 100$ in the code of GB50012.

(3) From the damage distribution of structural components, the concrete beam suffered from relatively serious earthquake damage, most concrete beams were within the acceptance criterion of LS and two beams exceeded the criterion of CP. Whereas, for the vertical structural components, only few shear walls exceeded the concrete yield compressive stress and most of the shear walls remained in the elastic stage. No frame column exceeded the criterion of $\mathrm{CP}$ were observed and most frame columns were within the component acceptance criterion of IO. It reflected that the building structure had sufficient seismic capability in rare earthquake. 


\section{References}

1. Wei Lian,Wang Sen,Wei Chengji. Torsional design method of asymmetric and irregular building under horizontal earthquake action. Building Structure, 2005 2(8): 12-17. (in Chinese)

2. Jiang Xinliang, Han Yang, Deng Zhendan. Horizontal and torsion displacement analysis on shaking table test of complex eccentric structure. Journal of Vibration Engineering, 2014, 27(2): 275-280. (in Chinese)

3. National Standards of People's Republic of China (2010). GB50011-2010 Code for seismic design of buildings, S. Beijing: Architecture and Building Press.

4. National Standards of People's Republic of China (2010). GB50010-2010 Code for design of concrete structures, S. Beijing: Architecture and Building Press.

5. PERFORM-3D Components and elements. CSI, 2006.

6. Prestandard and commentary for the seismic rehabilitation of buildings: FEMA 356. Washington D.C. : Federal Emergency Management Agency, 2000. 